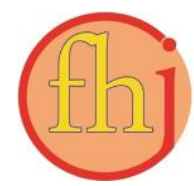

Faletehan Health Journal, 8 (2) (2021) 130-139

www. journal.Ippm-stikesfa.ac.id/ojs/index.php/FHJ

ISSN 2088-673X | e-ISSN 2597-8667

\title{
Studi Fenomenologi Pengalaman Ibu dengan HIV/AIDS dalam Mengasuh Anak
}

\author{
Dewi Rahmawati ${ }^{1}$, Eka Ernawati ${ }^{1 *}$ \\ ${ }^{1}$ Program Studi IImu Keperawatan, Universitas Faletehan \\ *Corresponding Author: ekakiki20@gmail.com
}

\begin{abstract}
Abstrak
Masalah yang ditimbulkan akibat penyakit HIV/AIDS dapat berdampak terhadap kehidupan ibu dengan HIV/AIDS dan berpengaruh terhadap kehidupan mengasuh anak. Kompleksitas pengaruh penyakit HIV/AIDS membantu ibu merubah pola asuh dalam merawat diri, anak dan keluarganya. Tujuan penelitian ini untuk mengetahui pengalaman ibu dengan HIV/AIDS dalam mengasuh anak. Desain penelitian menggunakan kualitatif dengan pendekatan fenomenologi. Hasil penelitian mendapatkan tiga tema yaitu: perubahan psikologis ibu dengan status HIV, harapan terhadap orang tersayang, dan pemilihan pola asuh dominan oleh ODHA kepada anaknya. Dampak penyakit HIV masih menimbulkan respon psikologis ibu dalam menerima kondisi sakit, yang berdampak terhadap pemilihan pola asuh yang dominan antara otoriter dan permisif. Kompleksnya permasalahan yang ditimbulkan akibat HIV/AIDS membutuhkan sistem layanan kesehatan terintegrasi lintas sektoral dengan departemen agama, pendidikan, dan sosial. Perlunya peningkatan layanan konselor di rumah sakit dan departemen agama untuk mengembangkan program atau topik konseling pranikah bagi pasangan yang akan menikah. Perlunya menyiapkan atau memperkaya tema bimbingan pranikah terutama resiko keluarga HIV ataupun penyakit menular lainnya. Departemen pendidikan sebaiknya mengadakan sosialisasi mengenai pendekatan dan pencegahan HIV bagi siswa sekolah. Departemen sosial perlu memastikan ketersedian fasilitas untuk layanan kesehatan sosial yang bisa menampung anak dengan HIV atau anak terdampak HIV.
\end{abstract}

Kata Kunci: HIV/AIDS, Pengalaman Hidup, Pola Asuh

\section{Phenomenology Study of Mother's Experience with HIV/AIDS in Child Care}

\begin{abstract}
The problems caused by HIV/AIDS may impact on the life of mothers with HIV/AIDS and affect the life of raising child. The complexity of HIV/AIDS effects helps mothers change their parenting styles in caring for themselves, their child and their family. The purpose of this study was to determine the experiences of mothers with HIV/AIDS in child care. The research design was qualitative with phenomenological approach. The results obtained three theme: psychological changes of mothers with HIV status, expectations for loved ones, the choice of dominant parenting style by PLWHA to their child. The impact of HIV disease still caused a psychological response to mothers in accepting their sick condition, impacting on the choice of dominant parenting styles between authoritarian and permissive. The complexity of the problems caused by HIV/AIDS required an integrated cross-sectoral health service system among department of religion, education and social affairs. It was important to Improve counseling services at hospitals and religion department to develop pre-marital counseling programs or topics for couples who will get married. It was also important to prepare or enrich themes of premarital guidance, especially the risks of HIV family or other communicable diseases. Education department should promote HIV approaches and preventions to students. Social department should ensure the availability of facilities for social health services that can accommodate children with HIV or children affected by HIV. Keywords: HIV/AIDS, Life Experience, Parenting Style
\end{abstract}


Faletehan Health Journal, 8 (2) (2021) 130-139

www. journal.Ippm-stikesfa.ac.id/ojs/index.php/FHJ

ISSN 2088-673X | 2597-8667

\section{Pendahuluan}

Pengalaman hidup wanita sebagai istri atau ibu dengan HIV/AIDS mempunyai fenomena tersendiri. Dampak yang ditimbulkan membutuhkan penanganan dan dukungan dari orang sekitar. Sebagai penderita, ibu dengan HIV berisiko mengalami permasalahan baik secara fisik, psikis, sosial maupun spiritual. Dari segi fisik penderita HIV akan mengalami masalah kesehatan berupa infeksi opportunistik akibat adanya penurunan kekebalan tubuh seperti TBC, kandidiasis dan diare kronis (Smeltzer \& Bare, 2010). Penurunan fungsi fisik secara umum akan berdampak pada kesejahteraan psikis. Beberapa masalah psikologis pada istri dengan HIV/AIDS diantaranya adalah rasa malu, takut dan adanya konflik internal dimana istri dengan HIV harus menutup diri terkait statusnya, baik terhadap anak, keluarga ataupun lingkungan sosial (Gillard, A., \& Mark, 2013). Menurut hasil penelitian Walulu, R \& Gill, (2011) ibu rumah tangga yang menderita HIV cenderung merahasiakan status sakitnya serta takut untuk membuka diri terkait status sakitnya kepada anaknya (Nyamathi et al., 2013).

Pada aspek sosial ekonomi pengalaman penderita HIV yang mengalami stigma menurut (Kohan et al., 2008) mengatakan bahwa perempuan dengan HIV yang mengalami stigma negatif dari masyarakat dapat berakibat pada kehilangan pekerjaan. Masalah pada aspek spiritual juga ditemukan apabila proses penerimaan penyakit mengalami kegagalan. Terjadi distres spiritual seperti hilangnya harapan, ketidakberdayaan dan rencana bunuh diri (Majumdar, B. 2004). Secara kumulatif dampakdampak negatif tersebut di atas dapat memperburuk kualitas hidup pada pasien dengan HIV/AIDS (Haroen, H., Juniarti, N., \& Windani, 2008); (Sun, H., Zhang, J., \& Fu, 2007); Solomon et al., 2008)).

Penyebaran HIV/AIDS di Provinsi Banten terus mengalami peningkatan setiap tahunnya. Hal ini dipengaruhi oleh beberapa faktor seperti posisi Provinsi Banten yang berada di jalur perlintasan Jawa - Sumatera, memiliki kawasan industri dan sarana transportasi berskala internasional dengan tingkat mobilitas penduduknya yang sangat tinggi, sehingga terjadi perubahan gaya hidup masyarakat. Sebagian mata pencarian masyarakat Banten bekerja di daerah Jakarta. Selain itu, Provinsi Banten berbatasan langsung dengan dua provinsi dengan tingkat prevalensi kasus HIV/AIDS yang sangat tinggi yaitu Provinsi DKI Jakarta dan Provinsi Jawa Barat (Komisi Penanggulangan AIDS Kabupaten Serang., 2018).

Kerentanan tertularnya istri diakibatkan banyak hal salah satunya adalah keengganan pasangan untuk memberitahukan statusnya sebagai penderita kepada orang lain (pasangan/ keluarga). Beberapa penelitian menyebutkan kuatnya stigma masyarakat termasuk keluarga dan pasangan terhadap penderita HIV menghalangi pasien untuk membuka status HIV-nya kepada pihak lain (de Souza, (2010); Thomas et al., (2009)). Literatur menurut Areas, D (2010) melaporkan dalam surveilance HIV, perempuan merupakan gender dengan HIV/AIDS yang lemah dalam pengambilan keputusan terkait pengelolaan penyakitnya, keputusan masih harus sesuai dengan aturan keluarga.

Kondisi ketidakpercayaan pasangan berdampak dalam tugas perkembangan keluarga. Keluarga mengalami konflik, dan terputusnya tugas perkembangan keluarga. Tingkat perceraian karena ditinggalkan oleh pasangan menjadi konflik dalam keluarga. Tugas perkembangan menjadi orangtua tunggal berdampak dalam pengasuhan anak. Dampak yang ditimbulkan dari aspek fisik, psikologis, sosial, spiritual menimbulkan perubahan dalam keluarga. Perubahan tersebut berdampak pada perubahan peran ibu (Ernawati, E., Rahayu, S., 2019).

Ibu berperan sebagai pencari nafkah dalam memenuhi kebutuhan hidup. Ibu sebagai orang tua tunggal, mengalami perubahan peran dikeluarga sebagai wanita pekerja. Perubahan tersebut yang menjadi salah satu masalah dalam kehidupan keluarga dengan HIV. Dibutuhkan pendekatan yang berbasis keluarga dalam pengobatan dan perawatan. Penelitian Karina., Hartati \& Endah (2009) didapatkan hasil bahwa seorang ibu dengan status HIV seringkali tidak mampu mengatasi penderitaan yang dialaminya, sebab berdasarkan persepsinya, ia memandang bahwa tidak mendapat dukungan dari orang - orang sekitar dan cenderung mendapatkan stigma negatif. Hal ini membuat ia gagal beradaptasi dan menerapkan pola asuh yang baik pada anaknya dan cenderung memilih jenis pola asuh permissiveness. Berdasarkan fenomena diatas, menjadi penting mengungkap secara mendalam pengalaman wanita dengan HIV/AIDS dalam pengasuhan anak di Serang Banten. 


\section{Metodologi Penelitian}

Desain Penelitian yang digunakan dalam penelitian adalah kualitatif dengan pendekatan fenomenologi deskriptif. Menurut Polit \& Beck (2014) penelitian fenomenologi menuntut gambaran yang diteliti dari pengalaman yang biasa sehari- hari. Pada penelitian ini peneliti mengungkap pengalaman ibu dengan status HIV dalam mengasuh anak. Desain fenomenologi yaitu suatu metode penelitian memiliki kontribusi dalam hal mendalami pemahaman tentang perilaku, tindakan dan gagasan masing-masing individu terhadap dunia kehidupannya melalui sudut pandang yang diketahui dan diterima secara benar (Afiyanti \& Rachmawati, 2014).

Dalam penelitian fenomenologi ini peneliti dan tim melakukan empat tahap proses, mengikuti Polit \& Beck (2014) yaitu (1) Tahap Bracketing yaitu peneliti menyimpan informasi terkait asumsi, pengetahuan serta kepercayaan terkait fenomena yang sedang diteliti, (2) Tahap Intuiting dimana peneliti masuk secara total ke dalam fenomena yang sedang diteliti, (3) Tahap Analizing dimana peneliti mengidentifikasi esensi terkait fenomena yang diteliti, (4) Tahap Describing dan Interpretating dimana peneliti menyusun setiap data yang sudah dikelompokkan ke dalam bentuk narasi yang bersifat luas.

Penelitian ini dilakukan di Puskesmas Serang Kota. Partisipan dalam penelitian ini adalah ibu dengan HIV/AIDS. Partisipan dalam penelitian ini diambil secara purposive dengan jumlah sampel berjumlah 7 orang. Adapun pertimbangan pemilihan partisipan dalam penelitian ini adalah (1) Partisipan adalah seorang ibu yang terdiagnosa HIV/AIDS serta tercatat sebagai pasien kelolaan Program HIV/AIDS Puskesmas Serang Kota, (2) Partisipan mendapatkan pengobatan ARV , dan (3) Kondisi umum baik, mampu berkomunikasi dengan baik dan kooperatif.

Data dikumpulkan dengan wawancara, alat bantu penelitian yang digunakan adalah voice recorder untuk merekam pembicaraan peneliti dan partisipan, serta catatan lapangan untuk membantu peneliti mencatat data tambahan selama proses wawancara berlangsung. Instrumen dalam penelitian kualitatif adalah peneliti utama beserta anggota peneliti. Kemampuan peneliti dalam menggali pengalaman individu menjadi kompetensi yang harus dimiliki. Peneliti beserta anggota peneliti sebelumnya telah mempunyai pengalaman melakukan penelitian kualitatif.
Setelah data dikumpulkan, peneliti beserta tim melakukan analisa data. Pada penelitian ini peneliti menggunakan analisis Colaizzi yaitu melengkapi analisisnya dengan melakukan klarifikasi kembali kepada partisipan. Tahap-tahap analisis data yang dilakukan berupa: Membaca keseluruhan deskripsi partisipan tentang fenomena yang sedang diteliti, memisahkan pernyataan- pernyataan signifikan, merumuskan makna dari setiap pernyataan signifikan, membuat setiap unit makna menjadi satu tema / cluster makna, mengintegrasikan setiap tema menjadi deskripsi yang lengkap, memvalidasi hasil analisis kepada partisipan, menyempurnakan hasil analisis dengan data yang diperoleh selama proses validasi. Setelah dilakukan analisis maka peneliti menemukan beberapa tema dalam penelitian ini.

Sebelum melaksanakan penelitian, peneliti telah mengajukan etik penelitian. Penelitian ini telah mendapatkan persetujuan dan ijin dari komite etik penelitian. Prosedur etik yang diajukan telah mendapatkan persetujuan pada komisi Etik StiKes BTH Tasikmalaya dengan No 017/kepkbth/V/2020. Setelah mendapatkan pernyataan etik maka peneliti beserta anggota bersiap untuk melakukan pengumpulan data. Penelitian ini juga dilaksanakan dengan mempertimbangkan prinsip prinsip etika penelitian dengan memenuhi The Five Right Of Human Subjects in Research dari Polit, D. F., \& Beck (2006).

\section{Hasil dan Pembahasan}

\section{Gambaran Karakteristik Partisipan}

Partisipan yang berpartisipasi pada penelitian ini bejumlah 7 orang. Partisipan pada penelitian ini menggunakan kode $\mathrm{P}$ yang selanjutnya digunakan untuk menggantikan penamaan sekaligus menggambarkan urutan wawancara yang telah dilakukan berupa P1, P2, P3, P4, P5, P6 dan P7. Partisipan pada penelitian ini memiliki rentang usia dari 25 tahun sampai dengan 57 tahun dan telah berstatus ODHA lebih dari 1 tahun. Partisipan merupakan pasien HIV kelolaan Puskesmas Serang Kota. Karakteristik pada penelitian ini yaitu partisipan berdomisli di wilayah Banten khususnya diwilayah kerja puskesmas Serang Kota. 7 partisipan pada penelitian ini seluruhnya berjenis kelamin perempuan. Wawancara mendalam pada 7 partisipan dilakukan di Puskesmas Serang Kota dengan sebelumnya menjelaskan maksud dan tujuan peneliti serta memberikan lembar informed consent sebagai lembar persetujuan partisipan. 
Faletehan Health Journal, 8 (2) (2021) 130-139

www. journal.Ippm-stikesfa.ac.id/ojs/index.php/FHJ

ISSN 2088-673X | 2597-8667

\section{Tema yang Ditemukan}

Pada bagian ini secara rinci menjelaskan tema yang teridentifikasi dari hasil penelitian. Tema tersebut dikelompokan berdasarkan beberapa kategori:

Tabel 1: Tema Hasil Penelitian

\begin{tabular}{cl}
\hline No & \multicolumn{1}{c}{ Tema } \\
\hline 1 & Perubahan psikologis ibu dengan HIV \\
2 & Harapan terhadap orang tersayang \\
3 & Pemilihan pola asuh dominan otoriter dan \\
& permisive oleh ODHA kepada anaknya \\
\hline
\end{tabular}

1. Perubahan psikologis ibu dengan status HIV Hasil penelitian dengan tema pertama yaitu terjadi perubahan psikologis ibu dengan status HIV yang diungkapkan oleh seluruh partisipan. Ungkapan tersebut berasal dari sub tema yaitu saat terjadi HIV ibu mengalami perubahan mental berupa terjadi kekecewaan dalam hidup, merasa dikhianati oleh suami, terjadi proses tawar menawar dengan penyakitnya, serta ada yang mengalami putus asa terhadap hidup dan ditinggalkan pasangan berikut ungkapannya:

“...Ye sempet terpukul sih waktu itu. Sempet terpukulnya apa saya mau mati jangan-jangan, kan namanya penyakit kaya gitu enggak ada obatnya gitukan. Terus ya kepikiran macemmacem kan. Apalagi saya lagi hamil gitukan. Mana umur anak saya yang 12 tahun masih kecil kan (menangis)" (P7)

“...Saya tidak menyangka suami tega melakukan perbuatan seperti ini kepada saya sehingga bisa sampai terkena HIV/AIDS...", "... Saat sedang sedih selalu muncul rasa kecewa pada suami”... "Saya merasa sedih karena harus menata ulang kehidupan saya bersama anak - anak" (P1)

“...Saya sempat merasa putus asa, saya merasa sedih berkepanjangan, saya merasa sedih diminta berpisah dengan suami oleh ayah saya..." (P2)

“...Terkadang merasa tidak kuat menjalani hidup, saya merasa seperti bosan hidup, "Jika tidak ingat anak, inginnya pergi jauh...kadang enggak kuat bener aja bu, kalau malam tuh sumpah kalau liat anak tu saya pengen pergi jauh... “, "...Saya sering ada keinginan untuk mengakhiri hidup... "(P3)

“...Mikir, benci gitu tuh ya sama Allah, bener ini bu, Cuma diri saya sendiri, karena emang ini kesalahan saya cuma kan coba kalau saya mikirnya itu bukan nikah sama suami itutuh yah, kadang mikir kesitu, kadang juga mikir, Ya Allah kenapa sih saya kaya gini, enggak kaya orang-orang normal..." (P4)

"...Bener bener kita dikasih ujian kaya ibarat kasar kata nya ngegantung diri aja rasanya..." ... "...saya sebagai hamba mu sudah ga sanggup lagi kata saya gituin kan, nah akhir nya petunjuk dari Allah..." (P6)

“...dia meninggalkan. Saya sebenernya sempet putus asa sih. Ngelamun sendiri gitukan masalah..." (P5)

Partisipan dalam penelitian ini terjadi perubahan psikologis dengan reaksi yang pertama setelah terdiagnosis HIV adalah perasaan syok, kaget, tidak percaya, khawatir, takut, bingung, gusar kemudian setelah timbul beberapa gejala terminal maka akan muncul respon emosional lain berupa menjadi mati rasa, frustasi, sedih, dan depresi (Rohmat, 2011). Hal ini ditemukan pula pada penelitian ini bahwa ada rasa tidak percaya, kecewa, tawar menawar terhadap hidup hingga respon putus asa dan depresi yang dirasakan oleh partisipan. Perubahan emosional yang terjadi sesuai dengan adanya perubahan penolakan, marah, depresi, tawar mawar dan menerima terhadap kondisi yang dialami salah atunya bersedih (Setyoadi, 2013).

Bersedih merupakan bentuk dari respon kehilangan status kesehatan yang ditunjukkan pertama kali oleh ODHA dalam bentuk shock dan tidak percaya terhadap infeksi HIV. Pada penelitian ini, reaksi sedih, kecewa diungkapkan oleh mayoritas partisipan dalam penelitian ini. Hal ini sejalan dengan penelitian Sarafina (2012) bahwa semua klien pada penelitiannya menunjukan reaksi kesedihan yang mendalam dengan menangis sepanjang waktu dan bahkan ada juga yang sampai mengungkapkan keinginan untuk bunuh diri karena terdiagnosis HIV. 
2. Harapan terhadap orang tersayang

Hasil penelitian dengan tema kedua yaitu adanya harapan pada orang tersayang yang diungkapkan oleh P2, P3, P5, P4 dan P7. Ungkapan tersebut berasal dari sub tema status HIV negatif pada anak, berharap anak kedua tidak dengan HIV, berharap kondisi suami kedua negatif HIV berikut ungkapan:

“...Saya merasa lega anak saya negative HIV,

Saya merasa masih memiliki harapan saat anak

saya negative HIV ...” (P2)

“..Alhamdulillah anak saya negative hiv...” (P3)

“...Alhamdulillah anak saya duaduanya,

Alhamdulillah negative...” (P5)

"...mudah-mudahan ini juga negative yah, makannya saya suruh minum obat gitu biar sidedenya juga sehat, Nah sayakan enggak tau kalau saya ini statusnya ODHA, pas udah gede, ketahuannya pas anak udah gede, anak saya udah gede, udah 5 tahun ..." (P4), (Sama suami yang kedua, suruh minum obat, suruh cek, dia juga cek Alhamdulillah negaitf yah) ...” (P4)

“... yang penting anak jangan sampai kena, Udah dicek disini. Hasilnya enggak ada. Alhamdulillah..." (P7)

Seseorang yang telah terdiagnosis HIV memiliki harapan agar dirinya tetap sehat sekaligus anak ataupun keluarga yang lain tidak memiliki nasib yang sama dengan dirinya, muncul harapan bahwa ibu dengan status HIV positif menginginkan agar anaknya negative dan tidak merasakan penyakit serupa seperti yang diungkapkan oleh partisipan kelima dan ketujuh. Pada saat anaknya dinyatakan negative tentunya ada perasaan bahagia dan berkurang rasa kecemasannyya seperti yang diungkapkan P2, P3, P4, P5 dan P7.

Hal ini sejalan dengan penelitian Utami (2017) bahwa pada penderita HIV AIDS khususnya wanita memiliki harapan. Harapan yang diinginkan hidup dalam keadaan yang sehat dan mampu mempertahankan derajat kesehatannya. Hasil penelitian ini didukung oleh penelitian Safitri $\mathrm{K}$ et al., (2019) yang mengatakan bahwa wanita dengan HIV dan AIDS memiliki keinginan kuat untuk tetap sehat dan dapat menjalankan aktifitas sehari - hari terutama berstatus single mother yang tingkat aktifitasnya jauh lebih tinggi, hal tersebut menjadi motivasi untuk diri sendiri.

Penelitian yang dilakukan oleh BalitBangKes, (2015) bahwa motivasi internal penderita HIV dan AIDS bertahan hidup dan tetap sehat menjadi salah satu alasan kepatuhan bagi penderita HIV dan AIDS dalam menjalani pengobatan. Faktor yang mempengaruhi optimisme hidup pederita HIV dan AIDS adalah mempunyai motivasi hidup yang kuat dalam diri penderita HIV dan AIDS. Dengan adanya sikap optimis, penderita HIV/AIDS tergerak untuk meningkatkan semangat untuk bekerja, motivasi untuk bertahan hidup, dan memiliki pikiran yang lebih positif. Selain harapan untuk sehat, lebih jauh lagi mereka menginginkan untuk sembuh secara total. Hal ini juga kembali diperjelas oleh penelitian oleh Safitri et al., (2019) yang mengataan bahwa wanita dengan HIV dan AIDS meskipun diawal fase terdiagnosis akan menghadapi keterpurukan saat mental, akan tetapi mereka tetap memiliki harapan kuat dari dalam diri serta lingkungan sekitarnya. Harapan untuk diri sendiri ada obat yang dapat menyembuhkan serta ingin sembuh dari penyakit.

Harapan berikutnya yang diinginkan PLWHA terutama ibu yang berperan menjadi istri berharap terhadap keluarga terutama anak yang menjadi sumber pendukung utama partisipan. Hal ini sejalan dengan pernyataan seluruh partisipan bahwa menginginkan anaknya tidak sampai tertular HIV dan bisa hidup selayaknya anak normal. Partisipan memiliki komitmen tetap mengurus kebutuhan anaknya sebaik mungkin dengan tetap berperan sebagai kepala keluarga. Mampu berperan sebagai ibu termasuk berupaya untuk mengoptimalkan pencegahan penularan selama bermain atau berinteraksi dengan anak.

Penelitian Indriastuti (2015) menjelaskan bahwa partisipan dalam penelitiannya memiliki komitmen yang bagus terhadap anaknya yaitu pada saat hamil dengan mempertahankan kehamilannya dan menjaga menjaga kehamilannya tetap sehat, melahirkan dan berupaya untuk merawat anaknya dengan baik meskipun partisipan mempunyai status HIV positif.

3. Pemilihan pola asuh dominan otoriter dan permisive oleh ODHA kepada anaknya

Hasil penelitian dengan tema ketiga yaitu adanya pemilihan pola asuh dominan otoriter dan permisive oleh ODHA kepada anaknya diungkapkan oleh P1, P3, dan P7. Ungkapan 
Faletehan Health Journal, 8 (2) (2021) 130-139

www. journal.Ippm-stikesfa.ac.id/ojs/index.php/FHJ

tersebut berasal dari sub tema pola asuh otoriter mengalami ketakutan terhadap ayah dan kekerasan dalam pengasuhan. Sub tema kedua dengan memandirikan anak secara dini. Sub tema ketiga dengan pola asuh permisive merasa kehilangan waktu dengan anak dan aktifitas bermain jarang dengan anak berikut ungkapan:

"...Saya mendidik anak saya dengan tegas dan terbuka, Anak saya merasa takut dengan ayahnya karena sering dimarahi, Ayahnya seringkali menyentil anak saya saat anak tidak mau diam "Saya takut mental anak saya terganggu jika sering dimarahi...", “...Saat anak saya sulit diatur, saya selalu kasih omongan agar anak saya nurut, saya takut - takuti kalau saya tidak akan pulang ke rumah..." (P1)

"...Anak - anak mengerti dengan tanggung jawab yang saya berikan" (P1) "Saya mendisiplinkan anak - anak saya saat mendidik merek...anak - anak diberitahu untuk tidak malu membantu ibunya mencari nafkah dengan berjualan" (P1)

“..Merasa sedih karena harus mengajarkan anak saya mandiri di usia masih kecil, semua serba sendiri, rasanya sedih, harus ngajarin anak jadi mandiri, apa-apa sendiri”, sekarang mah jarang lah ngurusin anak, paling mikirin buat jajan aja dulu.." (P3)

"...Saya merasa jarang mengurus anak saya, karena saya harus mencari nafkah...” (P3)

"...Marah (ketawa) kamumah coba sih kak, beresin apatah disapu jangan main aja ya Allah".. (P7)

Pada saat seorang perempuan khususnya ibu tertular HIV dan dinyatakan positif, maka akan muncul beragam respon baik fisik maupun beban psikologis. Tahapan yang akan dirasakan oleh pasien perempuan dengan status HIV diantaranya akan dihadapkan pada stigma diri, perubahan peran terutama pada perempuan yang ditinggal suaminya meninggal. Ia harus berhadapan dengan peran ganda sebagai kepala keluarga yang bekerja keras mencari nafkah, sebagai pasien yang tetap harus menjalani pengobatan rutin seumur hidupnya serta berperan sebagai ibu yang harus membesarkan dan mendidik anak tanpa pendampingan suami atau sosok ayah. Kompleknya masalah yang dialami mempengaruhi keseharian pasien terutama dalam penerapan pola asuh pada anaknya.

Pola asuh merupakan suatu implementasi dari pengambilan keputusan antara pasangan mengenai proses perkembangan anak, sosialisasi anak yang memiliki tujuan membentuk anak yang mampu bertanggungjawab serta memiliki kontribusi terhadap lingkungan sosialnya. Pola asuh tidak terlepas dari peran ibu atau mothering. Ibu memiliki peran memberikan pendidikan agar dapat memiliki penyesuaian yang baik serta mencapai kompetensi dalam pergaulan social (Karina., Hartati \& Endah, 2009). Terdapat beberapa pola asuh yang banyak diterapkan orang tua diantaranya: Pola asuh otoriter merupakan pola asuh dengan tipe penuh kehangatan dan menuntut. Orang tua yang menerapkan gaya pola asuh ini cenderung disiplin, membuat aturan ketat, sering membatasi, sering menerapkan larangan, memberikan hukuman menekankan pada nilai ketaatan dan mengharapkan aturan dipatuhi tanpa ada penjelasan. Anak yang mendapatkan gaya pengasuhan ini cenderung menjadi pribadi pemberontak, sangat ketergantungan, anak menjadi mudah minder, khawatir, kurang percaya diri, tingkat harga diri rendah serta tingkat depresi yang tinggi (Milevsky et al., 2007).

Pola asuh berikutnya yaitu pola asuh permisif. Pola asuh ini menggambarkan gaya orang tua yang cenderung kurang peduli, memberikan kebebasan secara luas untuk anaknya. Orang tua akan sulit mengontrol anaknya. Memberikan keleluasaan dinilai bagi orang tua sebagai bentuk kasih sayang yang diberikan pada anak. Orang tua pada gaya pengasuhan ini tidak menerapkan aturan, tidak ada control perilaku, sedikit menerapkan ekspektasi perilaku untuk anak - anak. Umunya dampak dari penerapan pola asuh ini adalah anak akan rendah dalam orientasi motivasi ekstrinsik dalam hal kegiatan sekolah ataupun dala pergaulan terutama pada kelompok remaja. Anak menjadi tidak memliki control diri dalam bertindak karena orang tua orang tua seringkali menyetujui terhadap semua dengan tuntutan dan kehendak anaknya. Semua kehidupan keluarga seolah-olah sangat ditentukan oleh kemauan dan keinginan anak (Rokhmah, 2015).

Selanjutnya pola asuh authoritative dimana pola asuh ini memiliki karakteristik orang tua yang bersikap hangat tetapi tetap memberikan ketegasan. Orang tua akan medorong anak mandiri dengan tetap memperhatikan batasan - batasan 
perilaku dan kendali tetap pada orang tua dalam tindakan atau keputusan anak. Orang tua pada gaya pola asuh ini dinilai berwibawa sehingga aka nada kecenderungan dampak positif pada perkembangan anak berupa keterampilan dalam kehidupan social lebih kompeten, anak menjadi tanggung jawab, dan otonom.

Dalam penelitian ini ditemukan partisipan yang cenderung menerapkan pola asuh permisif kepada anaknya, hal itu diungkapkan bahwa dirinya setelah terdiagnosa HIV/AIDS mengalami perubahan berupa berkurangnya intensitas dan keharmonisan terhadap anak, dirinya mengungkapkan bahwa yang saat ini lebih memperhatikan anaknya adalah kakek neneknya, sedangkan dirinya kurang memberikan perhatian kepada anak. Temuan ini sejalan dengan penelitian yang dilakukan Karina., Hartati \& Endah (2009), bahwa subjek sebagai orang tua dengan HIV/AIDS menunjukkan perubahan pola asuh ke arah pola asuh permisif, karena subjek cenderung menjadi individu yang pasif dan menarik diri dari lingkungannya, sikap subjek tersebut berpengaruh terhadap hubungan harmonis antara subjek dengan anaknya.

Hal ini disebabkan beberapa faktor diantaranya adanya kelelahan fisik pada ibu penderita HIV/AIDS karena respon penyakit dan beban psikologis. Menurut Damayanti, D \& Rusmala, D (2017) bahwa depresi dan kelainan hormon menjadi dua penyebab kelelahan fisik yang dialami pasien HIV. Salah satu factor resiko munculnya kelelahan karena keterbatasan energi pada penderita HIV. Pasien mudah lelah karena ada keterbatasan fisik dimana kebutuhan oksigen yang diperlukan untuk melakukan metabolism, mensintesa energi jauh lebih tinggi dibandingkan orang yang sehat (Black \& Hawks, 2014).

Penelitian Handayani et al., (2012) bahwa seorang ibu terutama ibu rumah tangga dengan status HIV positif mengalami perubahan fisik yang akan berpengaruhi pada kondisi psikologis berupa depresi. Manifestasi depresi pada pasien HIV berkaitan dengan proses biologis dari sistem imun (CD4) yang biasanya mengalami penurunan sehingga berdampak pada sistem imunitasnya. Umumnya Ibu rumah tangga dengan status HIV positif mengalami penurunan kondisi kesehatan seperti diare parah, gatal-gatal, bisul, jamur di mulut hingga penurunan nafsu makan yang menyebabkan penurunan berat badan secara drastis. Hal - hal tersebut tentunya juga akan berpengaruh pada kemampuannya menjankan peran secara maksimal terutama dalam mengasuh anak.

Faktor lain yang berpengaruh pada pemilihan pola pengasuhan permisif adalah peran ganda. Peran ganda sebagai kepala keluarga yang harus diemban ibu yang pada akhirnya banyak waktu tersita untuk mencari nafkah dengan berbagai kegiatan seperti menjadi pengasuh atau asisten rumah tangga atau berdagang. Hal ini diperkuat dengan penelitian Murphy et al., (2011) yang menyatakan bahwa keterbatasan atau perubahan fisik yang disebabkan perjalanan penyakit HIV/AIDS menyebabkan kelelahan atau fatique pada orang tua untuk melakukan sesuatu yang menyenangkan dengan anak. Sehingga orang tua terutama akan banyak kehilangan momen bermain dengan anak.

Pada penelitian ini juga ditemukan pola asuh dengan tipe otoriter. Dimana P1 dan P7 mendidik anak - anak mereka dengan tegas, dengan berbagai aturan, seringkali juga memberikan punishment baik secara fisik (dengan menyentil) atau secara verbal dengan dibentak atau dimarahi. Keputusan P1 dan P7 untuk menerapkan pola asuh ini karena partisipan khawatir akan keadaan anaknya dan tidak ingin anak mereka mengalami hal yang sama dengan orang tuanya yang terdiagnosa HIV/AIDS, karena itu maka partisipan cenderung untuk memberikan batasan-batasan kepada anak, memberikan hukuman dan merespon dengan kemarahan jika anak melakukan kesalahan, serta menuntut anak untuk selalu menuruti apa yang dikatakan partisipan sebagai orang tua.

Hal ini sejalan dengan penelitian Karina., Hartati \& Endah (2009) bahwa partisipan perempuan yang tidak mampu mengatasi tekanan psikologis akibat penyakit dan juga beban hidup akan membuat dirinya mengambil keputusan untuk bertindak ke arah koping negative dan berdampak munculnya kondisi hopeless. Pada akhisnya kondisi tersebut menimbulkan komunikasi tidak sehat antara ibu dan anak. Partisipan seperti akan menunjukkan sikap coercion dimana partisipan ibu akan berkomunikasi dengan anak dengan nada keras, membentak anak agar anak ketakutan da nada efek jera serta cenderung mengikuti perintah ibu. Selain itu, partisipan juga akan menggunakan teknik love withdrawl dimana akan menggunakan bentuk ancaman pada anak berupa meninggalkan anak jika perilaku buruk anak dirasa belum berubah. 
Faletehan Health Journal, 8 (2) (2021) 130-139

www. journal.Ippm-stikesfa.ac.id/ojs/index.php/FHJ

ISSN 2088-673X | 2597-8667

Partisipan ketiga menyampaikan bahwa adanya penyesalan pada saat harus keras dan memandirikan anak di usia dini, ia mengungkapkan bahwa anaknya menjadi lebih sulit diatur. Adanya kekhawatiran pada mental anak yang cenderung seringkali dimarahi. Bahkan salah satu anak pada P1 mengungkapkan ketakutannya pada orang tua yaitu ayahnya karena seringkali dimarahi. Hal ini tentunya akan berdampak pada perkembangan emosi anak ke di masa depan. Hasil ini sesuai dengan penelitian Lee et al., (2013) bahwa gaya pengasuhan akan berpengaruh signifikan pada kecerdasan emosional dan pembentukan perilaku anak. Gaya pengasuhan pada orang tua status positif HIV di Thailand dengan typical overprotektif pada anak dengan status positif HIV juga akan membentuk mereka menjadi pribadi dengan harga diri rendah, percaya diri yang kurang terbukti anak menyampaikan keluhannya seringkali stress dengan sikap orang tuanya kepada mereka sehingga sulit dalam sosialisasi dengan lingkungan luar karena terlalu dikekang atau dibatasi ruang geraknya.

Ungkapan positif dari gaya pengasuhan otoriter berdasarkan wawancara dengan partisipan. Didapatkan hasil bahwa P1 merasa dengan memandirikan anak sedari kecil akan dirasakan manfaatnya saat anak usia dewasa karena mereka menjadi mengerti dan tidak malu menjalani hidup dan bahkan membantu orang tua nya bekerja untuk memenuhi kebutuhan sehari - hari. Kemandirian yang ditanamkan sejak kecil oleh P1 pada anak anaknya menjadi bekal mereka untuk kuat menjalani tantangan kehidupan.

Gambaran gaya pengasuhan anak yang berbeda menjelaskan bahwa pola asuh yang diberikan oleh partisipan berbeda memilikin tujuan, penyebab dan dampak tertentu pada anak untuk pembentukan karakteristik emosi anak. Perubahan emosi mengalami proses denial atau pengingkaran karena status kesehatannya sehingga akan menimbulkan respon psikologi stress yang akan berdampak pada komunikasi dengan anak, orang tua akan memilih pola asuh permisif karena belum mampu menguatkan diri dengan beban mentalnya yang sedang terpuruk. Di pertengahan atau saat pasien menjalani pengobatan, masih akan ada berkecambuk respon marah dan tawar menawar terkait kondisinya dan penderita akan cenderung mulai ketakutan atau khawatir dengan kondisi penyakitnya yang akan menyebabkan kematian. Hal lain yang akan dirasakan adalah ketakutan akan status kesehatan anaknya dan kekhawatiran dengan masa depan anaknya sehingga pola asuh yang akan diterapkan ibu adalah otoriter dimana akan banyak pembatasan, aturan yang harus dipatuhi anak.

Pada fase terakhir, disaat partisipan berhasil memaknai kondisi sakit serta perannya sebagai ibu secara positif. Penghayatan partisipan terhadap makna sakit yang merupakan pemberian Tuhan membuatnya dapat menerima takdirnya dengan ikhlas. partispan percaya bahwa Tuhan akan selalu melindunginya dan anak-anak. Subjek menempatkan dirinya sebagai panutan bagi anakanak, karena itu partisipan akan sangat bersemangat untuk memberikan semua hal secara maksimal terhadap anak-anaknya. Kondisi emosional yang stabil memberi pengaruh besar pada kualitas kehangatan dan sensitivitas yang ditunjukkan ibu terhadap anaknya. partisipan tetap dapat menjaga attachment dengan anak-anaknya dengan terus membangun komunikasi yang hangat. partisipan juga berusaha untuk memahami kebutuhan-kebutuhan anak-anaknya serta berupaya untuk memenuhinya.

Pada penelitian ini nilai anak bagi perempuan single parent dengan HIV positif adalah lebih kepada nilai psikologis. Anak memberikan kebahagian bagi partisipan seperti halnya yang diungkapkan partisipan kesatu, kedua dan keempat. Anak menjadi sebuah alasan dan tujuan untuk tetap bertahan hidup walaupun tanpa pendampingan atau dukungan dari keluarga besar. Anak yang sudah lebih dewasa seperti partisipan kesatu dididik oleh partisipan untuk mandiri dalam mengerjakan tugas sehari - hari dan mencari nafkah sehingga bisa membantu meringankan beban orang tuanya. Sedangkan, pada partisipan lain yang memiliki anak balita maupun preschool, adanya dukungan keluarga seperti dari nenek maupun kakek membantu partisipan untuk tetap menjalani hidup dengan baik.

Perlu adanya peran dari tenaga kesehatan sebagai sistem pendukung dalam melakukan pengkajian komprehensif bukan hanya focus pada permasalahan fisik, namun permasalahan prikologis yang seringkali ditemukan pada wanita yang mengalami HIV/AIDS. Perlu adanya pemberian pendidikan atau edukasi terkait dengan parenting, pentingnya merancang pola pengasuhan pada anak agar tepat sesuai dengan kebutuha, tujuan pengasuhan, dan goal yang ingin dicapai 
orang tua terhadap anaknya di masa depan. Sehingga tidak terjadi keterlambatan perkembangan ataupun perilaku menyimpang yang terjadi pada anak di masa yang akan datang.

\section{Simpulan}

Penularan HIV/AIDS yang didapatkan istri/ ibu rumah tangga sebagai sumber penularan dari suami paling sering dialami. Hal tersebut pada akhirnya menjadi pemicu munculnya respon psikologis berupa perasaan dibohongi yang dialami seorang istri yang terdiagnosa HIV/AIDS akibat ketidaksetiaan dan ketidakjujuran dari pasangan. Perubahan psikologis masih terjadi ketika terdiagnosis HIV/AIDS dimulai dari rasa kecewa hingga depresi. Berbagai dinamika tersebut berdampak terhadap status kesehatan dirinya dan pola pikir dan pola asuh yang harus diterapkan ibu. Kompleksnya permasalahan yang ditimbulkan akibat HIV/AIDS perlu adanya sistem layanan kesehatan terintegrasi lintas sektoral dengan departemen agama, pendidikan, dan sosial. Peningkatan layanan konselor di Rumah Sakit dan departemen agama untuk mengembangkan program atau topik konseling pranikah bagi pasangan yang akan menikah. Menyiapkan tema atau memperkaya tema bimbingan pranikah terutama resiko keluarga HIV ataupun penyakit menular lainnya. Bagi departemen pendidikan sosialisasi mengenai pendekatan dan pencegahan HIV bagi siswa sekolah serta bagi departemen sosial ketersedian fasilitas untuk layanan kesehatan sosial yang bisa menampung anak dengan HIV atau anak terdampak HIV.

\section{Referensi}

Afiyanti \& Afiyanti \& Rachmawati. (2014). Metodologi Penelitian Kualitatif dalam Riset Keperawatan. PT Raja Grafindo Persada.

Areas, D. (2010). Diagnoses of HIV infection among adults and adolescents, by sex and transmission category , 2010 - 46 states and 5 U . S . dependent areas Males. Aids, 22.

Black \& Hawks. (2014). Keperawatan Medikal Bedah: Manajemen klinis untuk Hasil yang Diharapkan (8th ed.). Salemba Medika.

Damayanti Dewi; Dewi Rusmala. (2017). Stigma Pada Perempuan Single Parent Dengan Hiv Positif. 10(2), 55-66.

de Souza, R. (2010). Women living with HIV: Stories of powerlessness and agency. Women's Studies International Forum, 33(3),
244-252.

https://doi.org/10.1016/j.wsif.2010.01.006

Ernawati, E., Rahayu, S., \& K. (2019). Pengalaman Hidup Wanita (Ibu Rumah Tangga) Didiagnosis Hiv-Aids di Serang. 272-283.

Gillard, A., \& Mark, R. (2013). Support For Basic Psychological Needs in The Context of HIV Disclosure for Older You Children and Youth. Children and Youth Service Review, 3(1), 102-111.

https://www.sciencedirect.com/science/articl e/abs/pii/S0190740912004033

Handayani, F., Irawaty, D., \& Afiyanti, Y. (2012). Pengalaman Injecting Drug Users Living With Hiv/Aids (ILWHA) Menjalani Terapi Antiretroviral Saat Terapi Rumatan Metadon. Jurnal Keperawatan Indonesia, 15(2), 103108. https://doi.org/10.7454/jki.v15i2.34

Haroen, H., Juniarti, N., \& Windani, C. (2008). Quality of life in women with HIV/AIDS and women with partner has HIV/AIDS in West Java, Indonesia. 11(18), 1-13.

Indriastuti, A. (2015). Faktor-faktor yang Mempengaruhi Pencapaian Peran sebagai Ibu pada Perempuan dengan HIV / AIDS di Yogyakart. Mutiara Medika, 15(1), 75-83. http://etd.repository.ugm.ac.id/home/detail_p encarian $/ 84637$

Karina, Hartati, \& E. (2009). Memahami Pola Asuh pada Ibu yang Terinfeksi Human Immunodeficiency Virus. http://eprints.undip.ac.id/10935/1/Microsoft Word_-_JURNAL_KArina-M2Aoo5o73.pdf

Kohan, S., Beigi, N. M., Fathizadeh, N., \& Malbousizadeh, M. (2008). Original Article HIV positive women's living experiences. 13(4), 151-156.

Komisi Penanggulangan AIDS Kabupaten Serang. (2018). Laporan Quartal 15 GF (Global Found) Fase 2. https://jdih.serangkab.go.id/

Lee, S. J., Li, L., \& Thammawijaya, P. (2013). Parenting styles and emotional intelligence of HIV-affected children in Thailand. AIDS Care - Psychological and Socio-Medical Aspects of AIDS/HIV, 25(12), 1536-1543. https://doi.org/10.1080/09540121.2013.7932 64

Majumdar, B. (2004). An exploration of socioeconomic, spiritual, and family support among HIV-positive women in India. Journal of the Association of Nurses in AIDS Care, 
Faletehan Health Journal, 8 (2) (2021) 130-139

www. journal.Ippm-stikesfa.ac.id/ojs/index.php/FHJ

ISSN 2088-673X | 2597-8667

15(37-46).

https://doi.org/https://doi.org/10.1177/105532 9003261967

Milevsky, A., Schlechter, M., Netter, S., \& Keehn, D. (2007). Maternal and paternal parenting styles in adolescents: Associations with selfesteem, depression and life-satisfaction. Journal of Child and Family Studies, 16(1), 39-47. https://doi.org/10.1007/s10826-0069066-5

Murphy, D. A., Roberts, K. J., \& Herbeck, D. M. (2011). HIV Disease Impact on Mothers: What They Miss During Their Children's Developmental Years. Journal of Child and Family Studies, 20(3), 361-369. https://doi.org/10.1007/s10826-010-9400-9

Nyamathi, A., Ekstrand, M., Zolt-Gilburne, J., Ganguly, K., Sinha, S., Ramakrishnan, P., Suresh, P., Marfisee, M., \& Leake, B. (2013). Correlates of stigma among rural Indian women living with HIV/AIDS. AIDS and Behavior, 17(1), 329-339. https://doi.org/10.1007/s10461-011-0041-9

Polit, D. F., \& Beck, C. I. (2006). Essentials of Nursing Research: Methods, Apraisal, and Utilizations (Sixth Edit). Lippincot, William \& Wilkins. http://lib.ui.ac.id/

Polit, D. F., \& Beck, C. T. (2014). Essentials of Nursing Research Seventh Edition Appraising Evidence for Nursing Practice. In Lippincott Williams \& Wilkins.

Rohmat, M. S. (2011). Gambaran Konsep Diri Pada Orang Dengan Hiv / Aids Di Rumah Sakit Grhasia Provinsi Daerah Istimewa Program Studi Ilmu Keperawatan Sekolah Tinggi Ilmu Kesehatan 'Aisyiyah Yogyakarta Gambaran Konsep Diri Pada Orang Dengan Hiv / Aids Di Rumah Sakit Grhasia.

Rokhmah, D. (2015). Pola Asuh Dan Pembentukan Perilaku Seksual Berisiko Terhadap Hiv/Aids Pada Waria. Jurnal Kesehatan Masyarakat, 11(1), 125. https://doi.org/10.15294/kemas.v11i1.3617

Safitri K, Z., Amirudin, A., \& Margawati, A. (2019). Women Living with HIV/AIDS and Social Stigma in Semarang. Endogami: Jurnal Ilmiah Kajian Antropologi, 2(2), 131. https://doi.org/10.14710/endogami.2.2.131136

Sarafina, L. (2012). Pengalaman Hidup Perempuan Yang Terinfeksi HIV dalam Menjalani Kehamilan [Universitas
Padjajaran].

http://pustaka.unpad.ac.id/archives/111231

Setyoadi. (2013). The Experience of PLWHA Who Get Social Support Undergoing in Daily Life in Malang) October 2011. Jurnal Ners. https://www.researchgate.net/publication

Smeltzer, \& B. (2010). Brunner \& Sddarth's textbook of medical-surgical nursing (S. C. O. S. Suzanne C. Smeltzer (ed.); 12th ed.). Wolters Kluwer Health / Lippincott Williams \& Wilkins.

Solomon, S., Venkatesh, K. K., Brown, L., Verma, P., Cecelia, A. J., Daly, C., Mahendra, V. S., Cheng, N., Kumarasamy, N., \& Mayer, K. H. (2008). Gender-related differences in quality of life domains of persons living with HIV/AIDS in South India in the era prior to greater access to antiretroviral therapy. AIDS Patient Care and STDs, 22(12), 999-1005. https://doi.org/10.1089/apc.2008.0040

Sun, H., Zhang, J., \& Fu, X. (2007). Psychological status, coping and social support of people living with HIV/AIDS in Central China. Public Health Nursing, 24(2), 999-1005. https://doi.org/https://doi.org/10.1111/j.15251446.2007.00617.x

Teknologi, P., Kesehatan, I., \& Litbangkes, B. (2015). Gambaran Kepatuhan Orang Dengan Hiv-Aids (Odha) Dalam Minum Obat Arv Di Kota Bandung, Provinsi Jawa Barat, Tahun 2011-2012. Jurnal Kesehatan Reproduksi, $5(2)$, 113-123. https://doi.org/10.22435/jkr.v5i2Ags.3888.11 3-123

Thomas, B., Nyamathi, A., \& Swaminathan, S. (2009). Impact of HIV/AIDS on mothers in Southern India: A qualitative study. AIDS and Behavior, 13(5), 989-996. https://doi.org/10.1007/s10461-008-9478-x

Utami, E. (2017). Konsep Diri Wanita dengan HIV dan AIDS di Kota Makasar Tahun 2017 [Alaudin Makasar]. http://repositori.uinalauddin.ac.id/

Walulu, R \& Gill, S. (2011). Mother living with HIV disease: A Grounded Theory. 11(1). https://www.snrs.org/sites/default/files/SOJN R/2011/Vol11Num01Art03.pdf

Wojnar DM, S. K. (2007). Phenomenology: an exploration. J Holist Nurs, 25(3), 172-181. https://doi.org/DOI: $10.1177 / 0898010106295172$ 